\title{
Analysis of the Mercury Distribution in Blood as a Potential Tool for Exposure Assessment - Results from Two Artisanal and Small-Scale Gold Mining Areas in Zimbabwe
}

\author{
Anna-Maria Wahl ${ }^{1} \cdot$ Stephan Bose-O'Reilly ${ }^{1,2,3} \cdot$ Viola Mambrey $^{1} \cdot$ James P. K. Rooney $^{1,4} \cdot$ Dennis Shoko $^{5}$. \\ Dingani Moyo $^{6,7} \cdot$ Shamiso Muteti-Fana $^{8} \cdot$ Nadine Steckling-Muschack $^{1} \cdot$ Stefan Rakete $^{1}$ (D)
}

Received: 4 February 2021 / Accepted: 7 April 2021 / Published online: 23 April 2021

(C) The Author(s) 2021

\begin{abstract}
People in artisanal and small-scale gold mining (ASGM) areas are frequently exposed to high levels of mercury (Hg). Hg analyses in urine and whole blood are the gold standard of biomonitoring, although this may not provide sufficient information about the source of exposure, e.g., due to the use of $\mathrm{Hg}$ for gold extraction or due to nutrition. To evaluate, whether the pharmacokinetic properties of individual $\mathrm{Hg}$ species may be useful for exposure assessment, we determined the $\mathrm{Hg}$ levels in different blood components from 199 participants. Therefore, whole blood was centrifuged on-site to yield erythrocytes and plasma. Globin was isolated from the erythrocytes by precipitation with ethyl acetate. Albumin was isolated from plasma by gradual precipitation with saturated ammonium sulfate solution. $\mathrm{Hg}$ levels in all samples were determined by using a direct $\mathrm{Hg}$ analyzer. Median Hg levels for whole blood, erythrocytes, and plasma were 2.7, 3.7, and 1.3 $\mu \mathrm{g} / \mathrm{l}$, respectively. In globin and albumin, median $\mathrm{Hg}$ levels were 10.3 and $7.9 \mu \mathrm{g} / \mathrm{kg}$, respectively. The distribution of $\mathrm{Hg}$ was strongly correlated with whole blood $\mathrm{Hg}$ levels $(p<0.01)$ and the time between the last use of $\mathrm{Hg}$ and the date of the participation $(p<0.01)$. The results suggest that the distribution of $\mathrm{Hg}$ in blood is substantially affected by the extent and the frequency of the exposure to elemental $\mathrm{Hg}$. Therefore, the analysis of $\mathrm{Hg}$ in erythrocytes and plasma may be a valuable tool for $\mathrm{Hg}$ exposure assessment in ASGM areas.
\end{abstract}

Keywords Artisanal and small-scale gold mining · ASGM · Zimbabwe · Exposure assessment · Mercury $\cdot$ Human biomonitoring

\section{Introduction}

Despite its international condemnation, mercury $(\mathrm{Hg})$ is still heavily used in artisanal and small-scale gold mining (ASGM), which accounts for approximately $38 \%$ of the global annual $\mathrm{Hg}$ emissions [1]. Due to its simplicity, amalgamation of gold remains the primary method of choice in ASGM.

Stefan Rakete

Stefan.Rakete@med.uni-muenchen.de

1 Institute and Clinic for Occupational, Social and Environmental Medicine, University Hospital, LMU Munich, Ziemssenstr. 1, D-80336 Munich, Germany

2 Institute of Public Health, Medical Decision Making and Health Technology Assessment, Department of Public Health, Health Services Research and Health Technology Assessment, UMIT (Private University for Health Sciences, Medical Informatics and Technology), Hall in Tirol, Austria

3 University Children's Hospital Regensburg (KUNO-Clinics), University of Regensburg, Clinic St. Hedwig, Regensburg, Germany
On a global scale, 10 to 19 million people are involved, threatened by serious health consequences due to acute and chronic $\mathrm{Hg}$ exposure [2-5]. The primary exposure pathway in ASGM is the inhalation of elemental $\mathrm{Hg}$, which is primarily released during amalgam smelting. In fact, amalgam smelters had a significantly higher $\mathrm{Hg}$ body burden compared to gold panners or the general population living in ASGM areas [1].

4 Academic Unit of Neurology, Trinity Biomedical Sciences Institute, Trinity College Dublin, Dublin, Ireland

5 Tailjet Consultancy Services, Harare, Zimbabwe

6 School of Public Health, Faculty of Health Sciences, Occupational Health Division, University of the Witwatersrand, Johannesburg, South Africa

7 Faculty of Medicine and Faculty of Social Sciences, Midlands State University, Gweru, Zimbabwe

8 Department of Community Medicine, UZ College of Health Sciences, Harare, Zimbabwe 
In addition to elemental $\mathrm{Hg}$, the dietary uptake of methylmercury (MeHg, secondary exposure) is a serious contributor to $\mathrm{Hg}$ exposure, too [6].

In general, biomonitoring studies focus on the analysis of total $\mathrm{Hg}$ in whole blood or urine. However, this does not allow the exact determination of the source of exposure, which may require $\mathrm{Hg}$ speciation, e.g., by GC-CVAFS [7] or LC-ICP-MS [8]. Due to its strong affinity to sulfhydryl groups in proteins, $\mathrm{Hg}$ species can also be analyzed by proteomics [9-11]. Although $\mathrm{Hg}$ speciation provides the most accurate information for exposure assessment, all of these methods require sophisticated laboratory infrastructure that is likely not available in an average trace element laboratory. Alternatively, the pharmacokinetic properties of elemental $\mathrm{Hg}$ and $\mathrm{MeHg}$ may be used to identify the source of exposure. It is known that elemental $\mathrm{Hg}$ is almost equally distributed between erythrocytes and plasma, whereas $\mathrm{MeHg}$ is predominantly found in the erythrocyte fraction [12]. Consequently, different exposure scenarios may result in distinct distribution patterns of $\mathrm{Hg}$ in blood.

Therefore, the main objective of this study was the investigation of $\mathrm{Hg}$ distribution patterns in the blood of individuals that identified themselves as artisanal and small-scale gold miners from the districts of Kadoma and Shurugwi in Zimbabwe. This included the analyses of $\mathrm{Hg}$ levels in whole blood, erythrocytes, and plasma but also in the major blood proteins globin and albumin. Furthermore, the results were correlated with sociodemographic and exposure information to evaluate if $\mathrm{Hg}$ distribution patterns in blood can complement the exposure assessment in ASGM areas by using relatively simple methods.

\section{Methods and Materials}

\section{Study Population}

This study was designed as a cross-sectional epidemiological study. The local partners (DM, DS) selected Kadoma and Shurugwi as representative ASGM areas in Zimbabwe. The study centers were located at two hospitals in Shurugwi and Kadoma to perform the health assessments and specimen sampling. The target population of this study consisted of people that identified themselves as miners and were at least 18 years of age. The local partners established the first contact with the participants and organized the transport of the participants to the study locations. All participants received the participant information to inform them about the study, signed the consent form, and received US \$5 as compensation for the lost working day. Participation was voluntary at all times. From March 18th to March 29th, 2019, a total of 207 participants, 134 were from Kadoma and 73 from Shurugwi, were examined, and whole blood samples as well as urine were collected. Additionally, erythrocytes and plasma fractions were collected from 201 participants (for details, see below). Please refer to Mambrey et al. for details regarding the physical examinations and questionnaires [13]. The participants were informed of their results by the principal investigator in Zimbabwe (DM).

\section{Materials}

Ammonium sulfate was obtained from Roth (Karlsruhe, Germany). Isopropanol was obtained from Sigma-Aldrich (St. Louis, USA). Ethyl acetate, sodium chloride, and hydrochloric acid (30\%) were obtained from Merck (Darmstadt, Germany). All chemicals were at least of analytical grade.

\section{Sampling of Whole Blood, Erythrocytes, and Plasma}

Trained medical personnel took venous whole blood samples from each participant into a $7 \mathrm{ml} \mathrm{Li}$-heparin tube certified for trace metal analysis (Sarstedt@). The names of the participants were encoded, and the decoding form was kept separately by the principal investigator (D.M.). Whole blood was separated on-site into an erythrocyte and a plasma fraction by centrifugation. Aliquots of erythrocytes and plasma were pipetted into 2-ml cryovials and immediately cooled to $4{ }^{\circ} \mathrm{C}$, transported to Germany and frozen at $-18^{\circ} \mathrm{C}$ until further processing. This methodology was used at both study locations and carried out by the same research team.

\section{Isolation of Globin and Albumin}

After the transport of the samples to the laboratory, globin and albumin were isolated from the erythrocytes and plasma, respectively. Each sample was processed at least in duplicate. The isolation of globin and albumin was tested in preliminary experiments prior to this study (unpublished data).

Globin - Globin was isolated according to an existing literature protocol with some modifications [14]. In detail, the frozen erythrocytes were thawed at room temperature on a roll mixer. Thereafter, the sample was vortexed, and an aliquot of $0.5 \mathrm{ml}$ was used for globin isolation according to the protocol. After the final step, globin was yielded as a light gray solid and dried overnight in a fume hood after covering the centrifuge tube with cellulose tissue. The resulting white powder was directly analyzed or frozen at $-18^{\circ} \mathrm{C}$ until further use.

Albumin - Albumin was isolated according to an existing literature protocol with some modifications [15]. In detail, the frozen plasma fraction was thawed at room temperature on a roller mixer. After that, an aliquot of $0.5 \mathrm{ml}$ was pipetted into a $2 \mathrm{ml}$ centrifugation tube, and albumin was isolated by gradual precipitation with a saturated ammonium sulfate solution according to the protocol. After the first two additions of ammonium sulfate, samples were centrifuged for $15 \mathrm{~min}$ at 7300 and $13,000 \mathrm{~g}$, respectively, and the resulting supernatants were 
transferred into new tubes. After the final addition of ammonium sulfate, the sample was centrifuged at $13,000 \mathrm{~g}$ for 25 $\min$. The supernatant was discarded, and the precipitate was covered with cellulose tissue and dried overnight in a fume hood. Albumin was yielded as a white-yellowish crystalline powder. The samples were directly analyzed or stored at -18 ${ }^{\circ} \mathrm{C}$ until further use.

\section{Mercury Analysis}

Total Hg levels were analyzed in erythrocytes, plasma, globin, and albumin by means of direct mercury analysis (DMA- 80 evo, MLS-MWS, Leutkirch, Germany). Whole blood samples from the same participants were analyzed in a previous study [13]. For erythrocytes and plasma, $100 \mu \mathrm{l}$ were directly pipetted into the sample boats. For globin and albumin, between 8 and $25 \mu \mathrm{g}$ were weighed into the sample boats. All subsequent steps were part of the automated $\mathrm{Hg}$ analysis. $\mathrm{Hg}$ was detected by atomic absorption at $253.5 \mathrm{~nm}$. Quantitation is based on an external calibration. The detection limit for total $\mathrm{Hg}$ in whole blood, erythrocytes, and plasma was $0.05 \mu \mathrm{g} / \mathrm{l}$ using a sample volume of $100 \mu \mathrm{l}$. For isolated proteins, the detection limit was $0.5 \mu \mathrm{g} / \mathrm{kg}$ using a sample weight of $10 \mu \mathrm{g}$. Aqueous $\mathrm{Hg}$ standards $(10 \mu \mathrm{g} / \mathrm{l})$ and two certified reference materials (ClinChek ${ }^{\circledR}$, Recipe, Munich, Germany) for whole blood $(1.26$ and $6.87 \mu \mathrm{g} / \mathrm{l})$ were analyzed each day for internal quality assurance.

\section{Outcome and Explanatory Variables}

For this study, Hg levels in whole blood, erythrocytes, plasma, globin, and albumin were treated as outcome variables. Additionally, the ratio of the $\mathrm{Hg}$ levels in erythrocytes and plasma $\left(\mathrm{Hg}_{\mathrm{E} / \mathrm{P}}\right)$ were calculated and used for statistical analysis. Various factors that are associated with $\mathrm{Hg}$ exposure were collected during the field work, including sociodemographic factors, working conditions, and health-related data from the study participants as reported earlier were treated as explanatory variables [13]. In detail, information on age, gender, the last time $\mathrm{Hg}$ was used, exposure risk factors, fish consumption, alcohol consumption, malaria disease, and place of residence were used for this study. The risk of a higher exposure to $\mathrm{Hg}$ was evaluated through an exposure risk score (ERS), which ranges from 0 to 3, depending on the categories Mercury Storage, Retort Use and Work Clothes [13]. The following data were considered as possible confounders for Hg levels in blood: fish consumption, alcohol consumption, and malaria disease.

\section{Statistical Analysis}

For six of the 207 participants, erythrocytes and plasma samples were not collected during the field work. Furthermore, sample volumes from two participants were too low for protein isolation. Consequently, eight participants were excluded from further analysis. The remaining 199 participants had a complete set of $\mathrm{Hg}$ values for all five matrices (whole blood, erythrocytes, plasma, globin, and albumin). From this group, one participant was excluded from analysis because of sample contamination. In summary, the data from 198 participants were included in the statistical analysis. SPSS ${ }^{\circ}$ Statistics (Version 26, IBM Corporation, New York, USA) and R (version 3.6.2.) were used to analyze the data. Continuous variables were summarized using median, interquartile ranges, minimum, and maximum. Categorical and nominal variables were summarized using frequencies and percentages. Due to the non-parametric distribution of $\mathrm{Hg}$ levels, Spearman-Rho, Mann-Whitney $U$, Kruskal-Wallis, and Jonckheere-Terpstra tests were applied. Scatter plots, box plots, and density plots were used for visual representation. Finally, linear regression modelling was used to explore associations between log $\left(\mathrm{Hg}_{\mathrm{E} / \mathrm{P}}\right)$ and exposure factors adjusted for sociodemographic variables. A separate linear model was built for each exposure factor and in each case adjusted for gender, age, place of residence, and fish consumption. A model for time from last $\mathrm{Hg}$ contact was built without statistical adjustments due to a higher proportion of missing values for this variable.

\section{Threshold Values}

Threshold values by German Federal Environmental Agency (UBA) were used to stratify the results according to the $\mathrm{Hg}$ levels in whole blood [16]. In detail, samples with a whole blood $\mathrm{Hg}$ level of either below $5 \mu \mathrm{g} / \mathrm{l}$ (HBM-I), between 5 and $15 \mu \mathrm{g} / \mathrm{l}$, or above $15 \mu \mathrm{g} / \mathrm{l}$ (HBM-II) were assigned to stratified groups for statistical analysis.

\section{Results}

The sociodemographic data and available exposure factors of the study population are summarized in Table 1 and Table S1. Information on age, gender, living area, and fish consumption were available for all participants included in the analysis. Data for exposure risk, alcohol consumption, and malaria was available for $170(86 \%)$ participants, data on the most recent use of $\mathrm{Hg}$ for 88 participants (44\%).

\section{Mercury Levels in Whole Blood, Erythrocytes, Plasma, Globin, and Albumin}

The results of the $\mathrm{Hg}$ analyses in the blood components are given in Table 2. According to the threshold levels for $\mathrm{Hg}$ in whole blood by the UBA, 133 participants $(67 \%)$ were below the HBM-I value, 43 (22\%) between HBM-I and HBM-II, and $22(12 \%)$ above the HBM-II value. Theoretical whole blood 
Table 1 Demographic details of the study population

\begin{tabular}{|c|c|c|c|}
\hline Age & $\begin{array}{l}\mathrm{N} \\
\text { Median (Min.-Max.) }\end{array}$ & $\begin{array}{l}198 \\
38(18-77)\end{array}$ & \\
\hline & & $\mathrm{N}$ & $\%$ \\
\hline \multirow[t]{2}{*}{ Gender } & Males & 162 & $(81.8)$ \\
\hline & Females & 36 & $(18.2)$ \\
\hline \multirow[t]{2}{*}{ Living Area } & Kadoma & 128 & $(64.6)$ \\
\hline & Shurugwi & 70 & $(35.4)$ \\
\hline \multirow[t]{4}{*}{ Last time $\mathrm{Hg}$} & 1-2 days & 33 & (16.7) \\
\hline & 3 days -4 weeks & 38 & $(19.2)$ \\
\hline & $>4$ weeks & 16 & $(8.1)$ \\
\hline & Missing & 111 & $(56.1)$ \\
\hline Exposure risk score & 0 & 20 & $(10.1)$ \\
\hline \multirow{4}{*}{$\begin{array}{l}\text { (Exposure risk factors: Retort } \\
\text { use (yes/no). Work clothes at } \\
\text { home (no/yes). Hg storage } \\
\text { [no (at work/yes (at home)]) }\end{array}$} & 1 & 63 & $(31.8)$ \\
\hline & 2 & 59 & $(29.8)$ \\
\hline & 3 & 28 & $(14.1)$ \\
\hline & Missing & 28 & (14.1) \\
\hline \multirow[t]{2}{*}{ Fish consumption } & $<$ once a week & 41 & $(20.7)$ \\
\hline & $>$ once a week & 157 & $(79.3)$ \\
\hline
\end{tabular}

mercury levels calculated from $\mathrm{Hg}$ levels in erythrocytes and plasma correlated very well with actual levels of $\mathrm{Hg}$ in whole blood (Fig. S1). The Hg levels in all matrices were nonparametrically distributed. $\mathrm{Hg}$ levels in erythrocytes were on average higher than in whole blood and plasma (Table 2 and Fig. 1a). Similarly, $\mathrm{Hg}$ levels in globin were higher than in plasma (Table 2 and Fig. 1b). The Hg levels in all matrices were highly correlated to each other ( $r>0.65$, Table S2). Correlations were particularly strong for erythrocytes and globin as well as for plasma and albumin (Fig. S2).

\section{Correlations of $\mathrm{Hg}$ Levels in Whole Blood with $\mathrm{Hg}$ Levels in Erythrocytes, Plasma, Globin, and Albumin}

Table 3 shows that when outcomes were stratified by HBM values, median $\mathrm{Hg}$ levels for all matrices increased with higher HBM categories. With increasing whole blood $\mathrm{Hg}$ levels, a significantly higher percentage of $\mathrm{Hg}$ was found in plasma, resulting in a significantly lower $\mathrm{Hg}_{\mathrm{E} / \mathrm{P}}$ in samples with whole blood Hg levels above HBM-II when compared to the other groups (Fig. 2a).

\section{Correlation of Recent Mercury Exposure and Exposure Risk Factors on Mercury Levels in Erythrocytes, Plasma, Globin, and Albumin}

The Hg levels in all matrices except for erythrocytes significantly decreased with the time since last $\mathrm{Hg}$ use (Table 4). In contrast, $\mathrm{Hg}_{\mathrm{E} / \mathrm{P}}$ increased from the time of last $\mathrm{Hg}$ use (Fig. 2b). For exposure assessment, an exposure risk score (ERS) was used, with 0 being the lowest exposure risk and 3 the highest [13]. The Hg levels in all matrices were mainly positively correlated with an increasing number of risk factors (Table S3). However, no association between ERS and $\mathrm{Hg}_{\mathrm{E} / \mathrm{P}}$ was observed (Fig. S3).

\section{Correlation of Other Factors with Mercury Levels in Whole Blood, Erythrocytes, Plasma, Globin, and Albumin}

The Hg levels in whole blood and individual blood components were stratified by gender, fish consumption, alcohol consumption, and malaria disease (Table S4). Women had
Table 2 Results of the mercury analysis in the blood components of all samples ( $n=198, G M$ geometric mean)

\begin{tabular}{lllllll}
\hline & $\begin{array}{l}\text { Whole blood } \\
\mu \mathrm{g} / \mathrm{l}\end{array}$ & Erythrocytes & Plasma & $\begin{array}{l}\text { Globin } \\
\mu \mathrm{g} / \mathrm{kg}\end{array}$ & Albumin & $\mathrm{Hg}_{\mathrm{E} / \mathrm{P}}$ \\
\hline Minimum & 0.2 & 0.3 & 0.1 & 1.1 & 1.3 & 0.5 \\
25th perc. & 1.2 & 1.6 & 0.5 & 6.8 & 4.2 & 1.3 \\
Median & 2.7 & 3.8 & 1.3 & 10.4 & 7.9 & 2.3 \\
75th perc. & 6.3 & 8.0 & 4.1 & 21.4 & 15.8 & 5.0 \\
Maximum & 166.8 & 164.5 & 164.9 & 573.0 & 631.4 & 20.8 \\
\hline
\end{tabular}


Fig. 1 Density plots of the logarithmized $\mathrm{Hg}$ levels in liquids (a: Hg in whole blood (blue), erythrocytes (red), and plasma (green); results are given in $\mu \mathrm{g} / \mathrm{l}$ ) and isolated proteins (b: $\mathrm{Hg}$ in globin (blue) and albumin (red); results are given in $\mu \mathrm{g} / \mathrm{kg}$ )
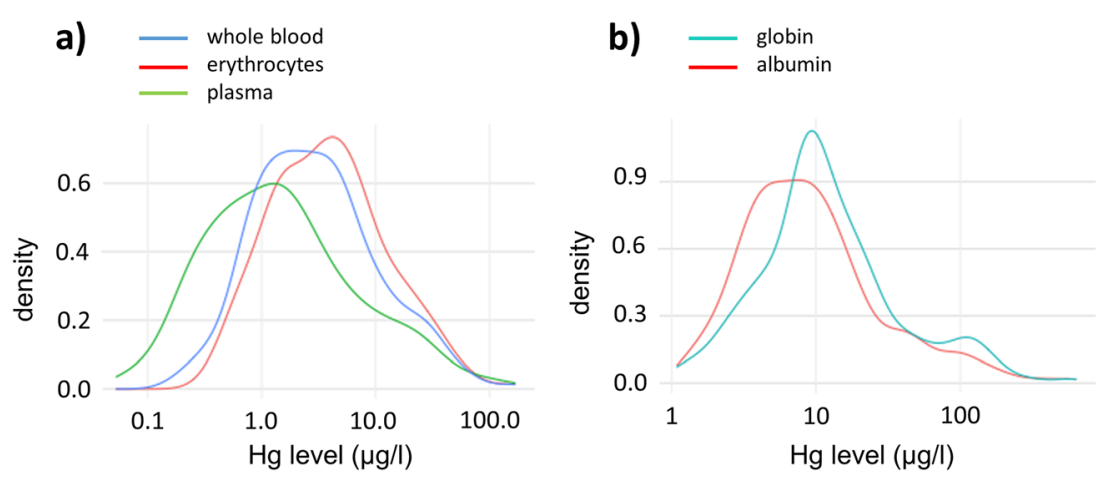

significantly higher $\mathrm{Hg}$ levels in all matrices, except for albumin. $\mathrm{Hg}_{\mathrm{E} / \mathrm{P}}$ was higher in women. However, the difference was not significant. $\mathrm{Hg}$ levels in all matrices were higher for participants that at least ate fish once a week, though a significant difference was only observed for erythrocytes. Although the $\mathrm{Hg}_{\mathrm{E} / \mathrm{P}}$ in this group was higher, too, the difference was not significant. For alcohol consumption and malaria disease, no significant differences were found.

\section{Linear Regression Modelling}

Results from multivariable linear regression models are shown in Table 5. Only never storing $\mathrm{Hg}$ at home was significantly associated with the $\log \left(\mathrm{Hg}_{\mathrm{E} / \mathrm{P}}\right)$ ratio with a parameter estimate of $0.50(95 \% \mathrm{CI}, 0.01-0.99 ; p=$ 0.044 ) after adjustment for gender, age, place of residence, and frequency of fish consumption. In the separate univariable model with the last time of $\mathrm{Hg}$ exposure as the explanatory variable and $\log \left(\mathrm{Hg}_{\mathrm{E} / \mathrm{P}}\right)$ as the outcome, having a last time from $\mathrm{Hg}$ exposure of over 4 weeks relative to 1 to 2 days was significantly associated with an increased $\log \left(\mathrm{Hg}_{\mathrm{E} / \mathrm{P}}\right)$ with a parameter estimate 0.879 (95\% CI, 0.436 to $1.322 ; p<0.001$ ). However, a last time from $\mathrm{Hg}$ exposure of 3 days to 4 weeks prior to the examination was associated with a higher ratio, but this parameter did not meet significance with an estimate of 0.312 (95\% CI, $-0.034,0.658 ; p=0.077)$.

\section{Discussion}

This cross-sectional study aimed to identify differences in the distribution of $\mathrm{Hg}$ levels between multiple blood components in participants identifying themselves as miners from two ASGM areas in Zimbabwe. In fact, the distribution of $\mathrm{Hg}$ in blood correlated with exposure factors such as the last time $\mathrm{Hg}$ was used at work. Furthermore, a linear relationship was observed between liquid blood components and their individual proteins.

Although the Hg levels in whole blood were lower than what has been found in other ASGM studies, they were still considerably higher than what can be expected in the general population $[17,18,19,20]$. In fact, one third of the participants were above the HBM-I value, which we used as threshold value. However, Hg levels in erythrocytes, plasma, globin, and albumin have never been analyzed thus far in individuals living and working in ASGM areas. Therefore, comparison of these values with other studies was not possible. Hg levels in globin and albumin were primarily analyzed to evaluate, if these proteins can be used for further investigations, e.g., for proteomic analysis. Although artifacts and loss of $\mathrm{Hg}$ during the isolation process cannot be excluded, we found a very strong linear relationship for erythrocytes and globin as well as for plasma and albumin. This indicates that the isolated proteins indeed resemble the $\mathrm{Hg}$ levels in erythrocytes and plasma, respectively.
Table 3 Stratification of $\mathrm{Hg}$ levels in erythrocytes, plasma, globin, and albumin by whole blood Hg levels (HBM categories)

\begin{tabular}{llllllll}
\hline & $n$ & $\begin{array}{l}\text { Whole blood } \\
{[\mu \mathrm{g} / \mathrm{l}]}\end{array}$ & Erythrocytes & Plasma & $\begin{array}{l}\text { Globin } \\
{[\mu \mathrm{g} / \mathrm{kg}]}\end{array}$ & Albumin & $\mathrm{Hg}_{\mathrm{E} / \mathrm{P}}$ \\
\hline$<$ HBM-I & 133 & 1.6 & 2.1 & 0.7 & 8.0 & 5.4 & 3.1 \\
$>$ HBM-I, $<$ HBM-II & 43 & 6.6 & 9.5 & 4.8 & 22.0 & 17.4 & 2.0 \\
$>$ HBM-II & 22 & 27.1 & 28.9 & 24.0 & 112.6 & 87.8 & 1.0 \\
$\mathrm{p}^{*}$ & & $<0.001$ & $<0.001$ & $<0.001$ & $<0.001$ & $<0.001$ & $<0.001$ \\
\hline
\end{tabular}

*Jonckheere-Terpstra test

All $\mathrm{Hg}$ values are given as medians. 
Fig. 2 Box plots of the $\mathrm{Hg}$ distribution in whole blood expressed by the ratio of $\mathrm{Hg}$ levels in erythrocytes and plasma $\left(\mathrm{Hg}_{\mathrm{E} / \mathrm{P}}\right)$ in relation to the $\mathrm{Hg}$ levels in whole blood (a, grouped by HBM categories) and the last time mercury was used (b). $* p<0.01$ (Kruskal-Wallis test)

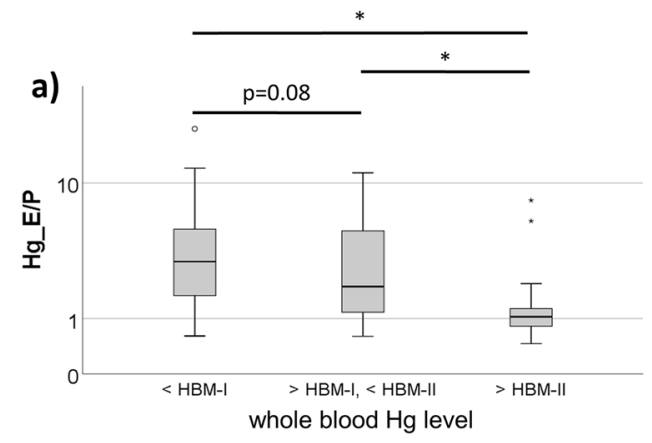

In general, $\mathrm{Hg}$ levels in all matrices were positively correlated with whole blood $\mathrm{Hg}$ levels, indicating that the exposure to $\mathrm{Hg}$ causes a ubiquitous increase of $\mathrm{Hg}$ levels in blood. However, this increase is not uniform. The distribution significantly correlated with whole blood $\mathrm{Hg}$ levels and the last time $\mathrm{Hg}$ has been used. An equal distribution between erythrocytes and plasma $\left(\mathrm{Hg}_{\mathrm{E} / \mathrm{P}}=1\right)$ indicates that these participants have likely been recently exposed to mainly elemental $\mathrm{Hg}$. Especially individuals with whole blood $\mathrm{Hg}$ levels above HBM-II showed a low $\mathrm{Hg}_{\mathrm{E} / \mathrm{P}}$, probably due to severe exposure to elemental $\mathrm{Hg}$, e.g., by smelting amalgam [18, 19]. Nevertheless, low $\mathrm{Hg}_{\mathrm{E} / \mathrm{P}}$ were also observed for participants with low whole blood Hg levels. After multivariable regression analysis, only never storing mercury at home was significantly associated with higher $\log \left(\mathrm{Hg}_{\mathrm{E} / \mathrm{P}}\right)$. Although higher $\mathrm{Hg}_{\mathrm{E} / \mathrm{P}}$ were also observed for those who eat fish at least once a week, this difference was not significant, and we had adjusted for fish consumption in regression models. Unfortunately, $\mathrm{Hg}$ levels in regional fish or other food were not available for a more precise assessment. Similarly, participants with low whole blood $\mathrm{Hg}$ levels and that have not been using $\mathrm{Hg}$ for more than 4 weeks showed a relatively high $\mathrm{Hg}_{\mathrm{E} / \mathrm{P}}$. This is in keeping with the shorter half-life of $\mathrm{Hg}$ in plasma compared to erythrocytes previously described in the literature [12]. Therefore $\mathrm{Hg}_{\mathrm{E} / \mathrm{P}}$ will likely increase with time after the exposure event. However, $\mathrm{Hg}_{\mathrm{E} / \mathrm{P}}$ may also be influenced by other sources of exposure as well as sociodemographic and genetic factors, too. Unfortunately, this data was unavailable, and the number of participants was too low to further explore the impact of these factors.

\section{Strengths and Limitations}

Limitations regarding the participants of this study were already addressed by Mambrey et al. [13]. In short, the poor economic situation and lack of prospects in Zimbabwe is a major reason why people are securing their livelihoods with ASGM. This leads to many illegal and poorly trained workers in gold mining. The participants may also self-identify as miners in order to obtain $\$ 5$ as compensation, and there was no possibility for the examiners to verify this information. Another general problem, not only concerning this study, was the fact that the individual miners have very different levels of exposure to elemental Hg. Some workers might have been continuously exposed and others just periodically [3]. In the end, exact exposure data was not available. Furthermore, speciation of $\mathrm{Hg}$ in the blood samples was not possible due to technical and financial limitations. This would have help to make assumptions about the source of exposure and help to explain distribution patterns of $\mathrm{Hg}$ in blood.

Additionally, the quality of the questionnaire data must be scrutinized regarding exposure and socioeconomic data. There is likely a recall bias, especially regarding the last time $\mathrm{Hg}$ was used and fish consumption, but also for exposure risk factors and others. This strongly influences the quality of the statistical analysis. Further limitations result from the protein isolation methods, which were not designed for $\mathrm{Hg}$ analysis. Consequently, the loss of $\mathrm{Hg}$ during the work-up and formations of artifacts cannot be completely excluded. To overcome this, we tested the isolation of proteins in preliminary
Table 4 Stratification of $\mathrm{Hg}$ levels in erythrocytes, plasma, globin, and albumin by the time since the last use of $\mathrm{Hg}$

\begin{tabular}{llllllll}
\hline & $\mathrm{n}$ & $\begin{array}{l}\text { Whole blood } \\
{[\mu \mathrm{g} / \mathrm{l}]}\end{array}$ & Erythrocytes & Plasma & $\begin{array}{l}\text { Globin } \\
{[\mu \mathrm{g} / \mathrm{kg}]}\end{array}$ & Albumin & $\mathrm{Hg}_{\mathrm{E} / \mathrm{P}}$ \\
\hline 1-2 days & 33 & 5.1 & 5.8 & 2.9 & 16.5 & 13.5 & 1.5 \\
3 days-4 weeks & 38 & 2.5 & 3.4 & 1.5 & 11.9 & 8.8 & 2.4 \\
$>$ 4 weeks & 16 & 2.0 & 3.5 & 0.6 & 8.5 & 4.5 & 4.5 \\
$p^{*}$ & & 0.017 & 0.029 & 0.001 & 0.013 & 0.001 & 0.001 \\
\hline
\end{tabular}

*Jonckheere-Terpstra test

All $\mathrm{Hg}$ values are given as medians. 
Table 5 Adjusted linear regression estimates of exposure risks vs log of the ratio of $\mathrm{Hg}$ in erythrocytes and plasma $\left(\mathrm{Hg}_{\mathrm{E} / \mathrm{P}}\right)$

\begin{tabular}{lllll}
\hline VariableqI & Estimate & $2.5 \% \mathrm{CI}$ & $95 \% \mathrm{CI}$ & $p$ value \\
\hline Retort use: yes & 0.02 & -0.31 & 0.36 & 0.888 \\
Work clothes at home: yes & -0.12 & -0.39 & 0.14 & 0.363 \\
Hg storage: at work & -0.09 & -0.37 & 0.18 & 0.512 \\
Hg storage: never & 0.50 & 0.01 & 0.99 & 0.044 \\
\hline
\end{tabular}

II All estimates adjusted for age, gender, district (Shurugwi or Kadoma), and fish consumption frequency

experiments prior to this study and could not observe significant losses or artifact formation during the work-up.

The strength of the study is the use of relatively simple methods for the assessment of the source, and time of exposure to elemental $\mathrm{Hg}$ is one of the strengths of this study, which only requires the separation of whole blood and individual analysis of in erythrocytes and plasma.

\section{Conclusion}

This is, to the best of our knowledge, the first study that addresses the distribution of $\mathrm{Hg}$ levels in erythrocytes and plas$\mathrm{ma}$ as a potential tool for the evaluation of sources of $\mathrm{Hg}$ exposure. Despite the uncertainties regarding the participant's questionnaire data, we were still able to identify $\mathrm{Hg}$ distribution patterns in blood depending on the exposure to elemental $\mathrm{Hg}$. In fact, the ratio of $\mathrm{Hg}$ levels in erythrocytes and plasma $\left(\mathrm{Hg}_{\mathrm{E} / \mathrm{P}}\right)$ was associated with recent exposure to elemental $\mathrm{Hg}$. Furthermore, this study showed that the isolation of globin and albumin from blood samples can be used for a more comprehensive analysis of $\mathrm{Hg}$ adducts, e.g., by mass spectrometry. In summary, the analysis of $\mathrm{Hg}$ in different blood components can provide useful information for $\mathrm{Hg}$ exposure assessment.

Supplementary Information The online version contains supplementary material available at https://doi.org/10.1007/s12011-021-02714-1.

Acknowledgements Open Access funding enabled and organized by Projekt DEAL. The authors like to thank all the participants for taking their time and making this project possible. Special thanks for all the support, logistic, and coordination in Zimbabwe, for making this project an exciting time and possible: Evans Rudzvidzo and the medical team including Dr. Godknows Madziva, Brian Chizaza, and Josephine Mashamba. We thank Myriam Tobollik for the additional help during the field work in Zimbabwe.

Author contribution Anna-Maria Wahl: sample preparation and analysis; data curation and analysis; visualization; writing, original draft; writing, review and editing. Stephan Bose-O'Reilly: funding acquisition; field work; conceptualization; project administration; supervision; writing, review and editing. Viola Mambrey: field work; data analysis; funding acquisition; writing, review and editing. James Rooney: data analysis; visualization; writing, review and editing. Dennis Shoko: field work; writing, review and editing. Dingani Moyo: field work; project administration; supervision; writing, review and editing. Shamiso Muteti-Fana: field work; writing, review and editing. Nadine Steckling-Muschack: funding acquisition; project administration; writing, review and editing. Stefan Rakete: conceptualization; funding acquisition; project administration; methodology; supervision; writing, review, editing, and final proof.

Funding This work was funded by the German Federal Ministry for the Environment, Nature Conservation and Nuclear Safety (BMU IG II 2 45083 - 4/0), and the Friedrich-Baur-Foundation (Reg.-Nr. 21/19). JR was funded by the EU Marie Skłodowska-Curie Action Research Fellowship Programme (846794 — MetALS).

Data availability Individual participant data will not be made available. Anonymized data may be made available upon reasonable request.

\section{Declarations}

Ethics approval To obtain ethical approval, the University Hospital of the Ludwig Maximilians University Munich (Germany) collaborated with Baines Occupational Health Services Centre (Zimbabwe) and the University of Zimbabwe. Approval had been obtained from the responsible health authorities at regional and district level as well as from the Zimbabwean Ministry of Health and Childcare. The ethics committees of the Ludwig Maximilians University Munich, Germany (18-421, October 15th, 2018) and the Medical Research Council of Zimbabwe (MRCZ/A/ 2367, September 26th, 2018, and February 25th, 2019) approved the protocol. The project was performed in accordance with the code of ethics of the Helsinki Declaration.

Consent to Participate Informed consent was obtained from all individual participants included in the study.

Consent for Publication The participants signed informed consent regarding publishing their data.

Conflict of Interest The authors have no conflicts of interest to declare that are relevant to the content of this article.

Open Access This article is licensed under a Creative Commons Attribution 4.0 International License, which permits use, sharing, adaptation, distribution and reproduction in any medium or format, as long as you give appropriate credit to the original author(s) and the source, provide a link to the Creative Commons licence, and indicate if changes were made. The images or other third party material in this article are included in the article's Creative Commons licence, unless indicated otherwise in a credit line to the material. If material is not included in the article's Creative Commons licence and your intended use is not permitted by statutory regulation or exceeds the permitted use, you will need to obtain permission directly from the copyright holder. To view a copy of this licence, visit http://creativecommons.org/licenses/by/4.0/.

\section{References}

1. UNEP (2019) Global mercury assessment 2018. UN Environment Programme, Chemicals and Health Branch, Geneva

2. Bose-O'Reilly S, Schierl R, Nowak D, Siebert U, William JF, Owi FT, Ismawati Y (2016) A preliminary study on health effects in villagers exposed to mercury in a small-scale artisanal gold mining 
area in Indonesia. Environ Res 149:274-281. https://doi.org/10. 1016/j.envres.2016.04.007

3. Bose-O'Reilly S, Bernaudat L, Siebert U, Roider G, Nowak D, Drasch G (2017) Signs and symptoms of mercury-exposed gold miners. Int J Occup Med Environ Health 30(2):249-269. https:// doi.org/10.13075/ijomeh.1896.00715

4. Esdaile LJ, Chalker JM (2018) The mercury problem in artisanal and small-scale gold mining. Chemistry 24(27):6905-6916. https:// doi.org/10.1002/chem.201704840

5. Steckling N, Tobollik M, Plass D, Hornberg C, Ericson B, Fuller R, Bose-O'Reilly S (2017) Global burden of disease of mercury used in artisanal small-scale gold mining. Ann Glob Health 83(2):234 247. https://doi.org/10.1016/j.aogh.2016.12.005

6. Ha E, Basu N, Bose-O'Reilly S, Dórea JG, McSorley E, Sakamoto M, Chan HM (2017) Current progress on understanding the impact of mercury on human health. Environ Res 152:419-433. https://doi. org/10.1016/j.envres.2016.06.042

7. Santa-Rios A, Barst BD, Basu N (2020) Mercury speciation in whole blood and dried blood spots from capillary and venous sources. Anal Chem 92(5):3605-3612. https://doi.org/10.1021/ acs.analchem. $9 \mathrm{~b} 04407$

8. Narukawa T, Iwai T, Chiba K, Feldmann J (2018) A method for methylmercury and inorganic mercury in biological samples using high performance liquid chromatography-inductively coupled plasma mass spectrometry. Anal Sci 34(11):1329-1334. https://doi.org/ 10.2116/analsci.18P255

9. Polacco BJ, Purvine SO, Zink EM, Lavoie SP, Lipton MS, Summers AO, Miller SM (2011) Discovering mercury protein modifications in whole proteomes using natural isotope distributions observed in liquid chromatography-tandem mass spectrometry. Mol Cell Proteomics 10(8):M110 004853. https://doi.org/10. 1074/mcp.M110.004853

10. Hogeback J, Schwarzer M, Wehe CA, Sperling M, Karst U (2016) Investigating the adduct formation of organic mercury species with carbonic anhydrase and hemoglobin from human red blood cell hemolysate by means of LC/ESI-TOF-MS and LC/ICP-MS. Metallomics 8(1):101-107. https://doi.org/10.1039/C5MT00186B

11. Janzen R, Schwarzer M, Sperling M, Vogel M, Schwerdtle T, Karst U (2011) Adduct formation of thimerosal with human and rat hemoglobin: a study using liquid chromatography coupled to electrospray time-of-flight mass spectrometry (LC/ESI-TOF-MS). Metallomics 3(8):847-852. https://doi.org/10.1039/C1MT00043H
12. Clarkson TW, Magos L (2006) The toxicology of mercury and its chemical compounds. Crit Rev Toxicol 36(8):609-662. https://doi. org/10.1080/10408440600845619

13. Mambrey V, Rakete S, Tobollik M, Shoko D, Moyo D, Schutzmeier P, Steckling-Muschack N, Muteti-Fana S, BoseO'Reilly S (2020) Artisanal and small-scale gold mining: a crosssectional assessment of occupational mercury exposure and exposure risk factors in Kadoma and Shurugwi, Zimbabwe. Environ Res 184:109379. https://doi.org/10.1016/j.envres.2020.109379

14. van Sittert NJ (2012) [N-2-cyanoethyl-valine, N-2-hydroxyethylvaline, N-methyl-valine (for the detection of exposure / exposure to acrylonitrile, ethylene oxide and methylating substances)]. In: The MAK-Collection for Occupational Health and Safety. pp 121. https://doi.org/10.1002/3527600418.bi0nmvld0012

15. Cioloboc D, Arkosi M-K, Silaghi-Dumitrescu R (2013) A new protocol for purifying human serum albumin. Studia Universitatis Babes-Bolyai, Seria Chemia 58(3):27-32

16. Schulz C, Wilhelm M, Heudorf U, Kolossa-Gehring M, Human biomonitoring commission of the German federal environment $\mathrm{A}$ (2011) update of the reference and HBM values derived by the German human biomonitoring commission. Int J Hyg Environ Health 215(1):26-35. https://doi.org/10.1016/j.ijheh.2011.06.007

17. Baeuml J, Bose-O'Reilly S, Matteucci Gothe R, Lettmeier B, Roider G, Drasch G, Siebert U (2011) Human biomonitoring data from mercury exposed miners in six artisanal small-scale gold mining areas in Asia and Africa. Minerals 1:122-143

18. Bose-O'Reilly S, Drasch G, Beinhoff C, Tesha A, Drasch K, Roider G, Taylor H, Appleton D, Siebert U (2010) Health assessment of artisanal gold miners in Tanzania. Sci Total Environ 408(4):796805. https://doi.org/10.1016/j.scitotenv.2009.10.051

19. Bose-O'Reilly S, Drasch G, Beinhoff C, Rodrigues-Filho S, Roider G, Lettmeier B, Maydl A, Maydl S, Siebert U (2010) Health assessment of artisanal gold miners in Indonesia. Sci Total Environ 408(4):713-725. https://doi.org/10.1016/j.scitotenv.2009.10.070

20. Wickliffe JK, Lichtveld MY, Zijlmans CW, MacDonaldOttevanger S, Shafer M, Dahman C, Harville EW, Drury S, Landburg G, Ouboter P (2020) Exposure to total and methylmercury among pregnant women in Suriname: sources and public health implications. J Expos Sci Environ Epidemiol 31:117-125. https://doi.org/10.1038/s41370-020-0233-3

Publisher's Note Springer Nature remains neutral with regard to jurisdictional claims in published maps and institutional affiliations. 